\title{
A prospective comparative study on uteroplacental blood flow, cardiac function and pregnancy outcome in women with heart disease and normal healthy pregnant women
}

\author{
Gayatri Mathuriya $^{1 *}$, Pooja Gondiya ${ }^{1}$, Ashish K. Jain ${ }^{2}$
}

\begin{abstract}
${ }^{1}$ Department of Obstetrics and Gynecology, ${ }^{2}$ Department of Medicine, Mahatma Gandhi Memorial Medical College, MY Hospital, Indore, Madhya Pradesh, India
\end{abstract}

Received: 22 April 2018

Accepted: 23 May 2018

\author{
*Correspondence: \\ Dr. Gayatri Mathuriya, \\ E-mail: drgayatrimathuriya@gmail.com
}

Copyright: () the author(s), publisher and licensee Medip Academy. This is an open-access article distributed under the terms of the Creative Commons Attribution Non-Commercial License, which permits unrestricted non-commercial use, distribution, and reproduction in any medium, provided the original work is properly cited.

\begin{abstract}
Background: Cardiac dysfunction in women with heart disease results not only in cardiovascular complication, but also lead to abnormal uteroplacental flow pattern, thus compromising normal growth and development of the fetus and contributing to complication of pregnancy. Our aims include, study the distribution of the type of heart diseases, Grading of the subjects according to NYHA classification, to study the cardiovascular and uteroplacental Doppler flow pattern and their obstetrics and fetal outcome in heart diseases subjects and controls groups.

Methods: This was a case control Prospective Comparative Study of 54 cases with Heart Diseases (cases) and 50 cases of normal healthy pregnant (control) admitted in Obstetrics and Gynaecology department.

Results: Our study shows the correlation of abnormal ECHO and uteroplacentation flow, abnormal ECHO were seen in 20 cases out of them 11 cases (55\%) had abnormal flow and 9 cases (45\%) had normal flow In our study it was observed that among the cases with abnormal ECHO 37\% (20 cases) 6 babies were handover healthy, 11 babies were went to nursery and $3(5.56 \%)$ babies were IUD among control group ECHO of all the control were normal. And Uteroplacental Doppler flow was abnormal among 15 cases $(27.7 \%)$ out of them 3 babies were healthy 9 babies went to nursery and 3 were IUD (5.56\%) and colour doppler of control group is normal in most of the cases.

Conclusions: Uteroplacental flow patterns of heart disease and healthy women relate these to cardiovascular parameters and to events and outcome in pregnant women .we will refine risk stratification that will lead to better prepregnancy counseling and may eventually improve treatment of these women by identifying the components responsible for pregnancy-related events in women with heart disease.
\end{abstract}

Keywords: Echocardiograhy, Fetomaternal outcome, Uteroplacental doppler flow

\section{INTRODUCTION}

Cardiac diseases complicate $0.2-4 \%$ of all pregnancy in western countries. ${ }^{1}$ In developing countries like India cardiac diseases complicates $1-2 \%$ of pregnancy and constitute to about one fifth of maternal death. ${ }^{2}$ Pregnancy in these women is associated with cardiovascular complication moreover, also obstetrics and offspring complication are more prevalent than in healthy women. ${ }^{3-7}$
Pregnancy itself is a circulatory burden, primarily due to volume overloading which has an impact even on healthy women. It is important to understand that even in normal patients pregnancy imposes some dramatic physiological changes upon the cardiovascular system. An important study by Clark and colleague (1989) contribute greatly to the understanding of cardiovascular physiology during pregnancy, in normal pregnancy cardiac output increase by $43 \%$ above pre pregnancy levels caused by rise in stroke volume. Plasma volume reaches its maximum of 
$40 \%$ and mean heart rate increase by 10 to 20 beats peaking in third trimester, there is decrease in vascular resistance, systemic by $21 \%$ and that of pulmonary by 34 $\%{ }^{8}$

Cardiac dysfunction in women with heart disease results not only in cardiovascular complication, but also lead to abnormal uteroplacental flow pattern, thus compromising normal growth and development of the fetus and contributing to complication of pregnancy.

\section{METHODS}

The resent study entitled comparative study on Uteroplacental Blood Flow, Cardiac Function And Pregnancy Outcome In Women With Heart Diseases And Normal Healthy Pregnant Women was conducted in the department of obstetrics and gynaeccology, M.G.M. medical college and my hospital, Indore, Madhya Pradesh, India during the period from august 2016 to July 2017. Each patient was told about her inclusion and participation in this study and her informed consent was taken. This was a case control prospective comparative study performed on 54 Cases with Heart Diseases (cases) and 50 cases of normal healthy pregnant (control).

Patients were evaluated by both cardiologists and obstetricians regularly and investigations including ECG and Echocardiography at 20 and at 32 weeks were done. Gestational age of the women was calculated from the last menstrual period, clinical examination and ultrasonography were done. Fetal conditions were assessed by clinical examination, ultrasonography and Biophysical profile and colour Doppler.

\section{Inclusions criteria}

Antenatal patients with heart diseases and healthy pregnant women who provided written informed consent coming to opd or labour room of M.Y. Hospital.

\section{Exclusion criteria}

Miscarriage or termination of pregnancy $<20$ wk of gestation antenatal patients with other medical disorders like thyroid, renal diseases and who is unwilling /unable to give written informed consent.

Data was transcribed from the proforma to Microsoft excel and the transferred to statistical package IBMSPSS Version for analysis comparition of the means between the group was done using unpaired ' $t$ ' test. Non parametric data was analyzed using Pearson's chi-square test/Mann Whitney U test. A p value of $<0.05$ was taken as statistically significant. The final data was presented in form of tables and graphs.

\section{RESULTS}

The grouping was done as case and control, cases were all patient of heart disease and controls were normal healthy pregnant women.

There were 74 cardiac patients admitted during the same period, giving an incidence of $0.2 . \%$ of heart disease during pregnancy, out of them 54 were studied after satisfying inclusion criteria and 50 normal healthy pregnant women were studied.

The facts which were observed during this study are discussed under following headings, among the type of heart disease $47(87 \%)$ cases were suffering from rheumatic heart disease while only $7(13 \%)$ cases had congenital heart disease and most common defect was mitral stenosis (22\%) and ASD was most common congenital heart diseases that maximum no. of cases were in age group 21-25 years, mean age is $24 . .32$ years \pm 2.2 followed by cases in age group 26-30 years and similar condition were seen in control group with, $\mathrm{p}=0.9426$.

There were more no. of cases in primigravida followed by multigravida similarly seen in control group, $\mathrm{p}=0.447$.

Maximum no. of cases were in NYHA grade I (70\%) and among control group all $(100 \%)$ belongs to NYHA grade I. Study shows that $17(31 \%)$ cases were booked cases and $37(69 \%)$ were admitted in emergency and all control group were booked case, $\mathrm{p}$ value $=0.001$.

Table 1: Age and parity wise distribution of cases.

\begin{tabular}{|llllll|} 
& Cases & & Control & P value \\
\hline Booked & No. & \% & No. & \% & \\
\hline Emergency & 17 & 31 & 50 & 100 & 0.001 (not significant) \\
\hline Primigravida & 37 & 69 & 00 & 00 & 0.447 (not significant) \\
\hline Multi Gravida & 34 & 63 & 35 & 70 & 0.9426 (not significant) \\
\hline $21-25$ yrs. & 20 & 37 & 15 & 30 & \\
\hline $26-30$ yrs. & 36 & 66.67 & 33 & 66 & 34 \\
\hline$>30$ & 18 & 33.33 & 17 & 00 & \\
\hline
\end{tabular}


Table 2: Outcome of pregnancy.

\begin{tabular}{|c|c|c|c|c|c|}
\hline \multirow{2}{*}{ Functional grade } & \multicolumn{2}{|c|}{ Cases } & \multicolumn{2}{|c|}{ Control } & \multirow[t]{2}{*}{ P value } \\
\hline & No. & $\%$ & No. & $\%$ & \\
\hline I & 38 & 70 & 50 & 100 & \\
\hline II & 14 & 26 & 00 & 00 & \\
\hline III & 02 & 4 & 00 & 00 & \\
\hline IV & 00 & 00 & 00 & 00 & \\
\hline Spontaneous vaginal delivery & 28 & 51.85 & 45 & 90 & 0.006 (significant) \\
\hline L.S.C.S. & 07 & 12.96 & 03 & 06 & \\
\hline Ventouse & 08 & 14.81 & 01 & 02 & \\
\hline Premature delivery & 11 & 20.37 & 02 & 04 & \\
\hline Total & 54 & 100.00 & 50 & 100 & \\
\hline C.C.F. & 2 & 3.70 & 00 & 00 & \\
\hline Pulmonary Edema & 2 & 3.70 & 00 & 00 & \\
\hline Atrial Fibrillation & 8 & 14.81 & 00 & 00 & \\
\hline Preeclampsia & 5 & 9.25 & 00 & 00 & \\
\hline Gestational Hypertension & 5 & 9.25 & 00 & 00 & \\
\hline PPH & 1 & 1.85 & 1 & 2 & \\
\hline Total & 23 & 42.59 & 1 & & \\
\hline
\end{tabular}

Table 3: Perinatal outcome according to echo at 20 weeks according to echo.

\begin{tabular}{|llll|}
\hline ECHO & No. of cases & Percentage & P value \\
\hline Healthy & 6 & 11.11 & $\begin{array}{l}0.007 \\
\text { (significant) }\end{array}$ \\
\hline Nursery & 11 & 20.37 & \\
\hline IUD & 3 & 5.56 & \\
\hline Total & 20 & 37.04 & \\
\hline
\end{tabular}

Table 4: Perinatal outcome according to uteroplacental blood flow.

\begin{tabular}{|llll|}
\hline $\begin{array}{l}\text { Uteroplacental } \\
\text { flow }\end{array}$ & $\begin{array}{l}\text { No. of } \\
\text { cases }\end{array}$ & Percentage & P value \\
\hline Healthy & 3 & 5.56 & 0.001 \\
\hline Nursery & 9 & 16.67 & \\
\hline IUD & 3 & 5.56 & \\
\hline Total & 15 & 27.78 & \\
\hline
\end{tabular}

Our shows that $52 \%$ of cases delivered spontaneously. L.S.C.S. done in $12 \%$ ( 7 cases). Ventouse applied in 8 cases and premature deliveries in $20 \%$ cases. Among the control group $90 \%$ patients delivered spontaneously and LSCS done for 6 cases Pearson Chi-Square $=17.16, \mathrm{P}$ valve is 0.006 . shows that $52 \%$ of cases delivered spontaneously. L.S.C.S. done in $12 \%$ (7 cases). Ventouse applied in 8 cases and premature deliveries in $20 \%$ cases. Among the control group $90 \%$ patients delivered spontaneously and LSCS done for 6 cases, $\mathrm{P}$ valve is 0.006 .

Only 8 cases had Atrial Fibrillation and equal no of cases had preeclampsia and gestational hypertension. I.e. $9.25 \%$ (5 cases) and 2 cases each of out of cardiac complication $\mathrm{CCF}$ and pulmonary edema.

Among the cases with abnormal ECHO 12.96\% (20 cases) 2 babies were handover healthy, 3 babies were went to nursery and $2(5.56 \%)$ babies were IUD, among control group ECHO of all the control were normal, $\mathrm{p}=0.001$ Among the cases with abnormal ECHO finding i.e. $37 \%$ (20 cases) 6 babies were handover healthy, 11 babies were went to nursery and $3(5.56 \%)$ babies were IUD among control group ECHO of all the control were normal.

Table 5: Correlation of echo and uteroplacental flow.

\begin{tabular}{|c|c|c|c|c|c|c|c|}
\hline \multirow{3}{*}{ Echo } & \multicolumn{4}{|c|}{ Uteroplacental flow } & \multirow{2}{*}{\multicolumn{2}{|c|}{ Total }} & \multirow{2}{*}{$\begin{array}{l}\text { P value } \\
\text { 0.001 (significant) }\end{array}$} \\
\hline & \multicolumn{2}{|c|}{ Abnormal $(n=15)$} & \multicolumn{2}{|c|}{ Normal (n=39) } & & & \\
\hline & No & $\%$ & No & $\%$ & No & $\%$ & \\
\hline Abnormal $(n=20)$ & 11 & 55 & 9 & 45 & 20 & 37 & \\
\hline Normal $(n=34)$ & 4 & 12 & 30 & 88 & 34 & 63 & \\
\hline Total & 15 & 28 & 39 & 72 & 54 & 100 & \\
\hline
\end{tabular}


Uterolacental flow was abnormal among 15 cases $(27.7 \%)$ out of them 3 babies were healthy 9 babies went to nursery and 3 were IUD $(5.56 \%)$. Our study shows the correlation of abnormal ECHO and uteroplacental flow, abnormal ECHO were seen in 20 cases out of them 11 cases $(55 \%)$ had abnormal flow and 9 cases (45\%) had normal flow that there were more no. of low birth weight babies among delivered heart disease patients (39\%). Among non-cardiac patients low birth weight babies were only $10 \%$ This shows that among cardiac cases( $53 \%$ ) babies were healthy and $40 \%$ babies went to nursery and 3 were IUD, comparatively to non cardiac case $82 \%$ were healthy and rest went to nursery and no death were seen among controls. Pearson ChiSquare $=9.44, p=0.002$,

This table shows that 9 babies were I.U.G.R. and 10 were preterm births in cardiac whereas 5 were IUGR and no baby were delivered preterm in non cardiac that mostly babies were alive and discharged healthy i.e. $94.4 \%$ among cardiac and $100 \%$ among non cardiac. This shows that $98.15 \%$ patient were discharged healthy among cardiac whereas $100 \%$ control were discharged healthy.

\section{DISCUSSION}

In our study maximum no. of cases were less than $25 \mathrm{yrs}$ (66.67\%) among cases $(66.67 \%)$ and control (66\%) with mean age $24.32 \pm 2.2$ years. Most of the patients belong to primigravida $63 \%$ in cases and $70 \%$ in control. A study on CHD and healthy cohorts were well balanced with respect to maternal age at conception $(28.7 \pm\} 4.4$ versus $29.2 \pm 4.5$ in control group, $\mathrm{p}=0.44)$, parity $(64.1 \%$ versus $62.9 \%$ nulliparous, Sawhney et al who found mean $( \pm \mathrm{SD})$ maternal age was $25( \pm 4)$ years,. parity $0.7 \pm 0.8 .^{9,10}$ Present study shows that maximum no. of cases were in NYHA grade I $(70 \%)$ in grade II $(26 \%)$ and only $(4 \%)$ in grade III and among control group all $(100 \%)$ belongs to NYHA grade I. finding were comparative to Sawhney et al who found that among heart diseases patients 95.4 percent belongs to class I and II and 4.8 percent in class III. ${ }^{10}$

Present study shows that out of 54 cases, $52 \%$ of cases i.e. 28 patients delivered spontaneously. L.S.C.S. done in $12 \%$ ( 7 cases) with all obstetric indication. Ventouse applied in 8 cases. Among the total 50 cases in control group $90 \%$ patients delivered spontaneously and LSCS done for 6 cases i.e. $6 \%$ patients. A study done by Hameed et al showed mode of delivery was vaginal in 61 (92\%) out of 66 patients with valvular heart disease and others had cesarean section due to obstetric indications and cardiac lesions, Bonow et al showed mode of delivery was vaginal in $196(78.1 \%)$ out of 251 and cesarean section done on $55(21.9 \%)$ patients. ${ }^{11,12}$

In present study it wasobserved that among the cases with abnormal ECHO 37\% (20 cases) 6 babies were handover healthy, 11 babies were went to nursery and $3(5.56 \%)$ babies were IUD among control group ECHO of all the control were normal. And Uteroplacental Doppler flow was abnormal among 15 cases $(27.7 \%)$ out of them 3 babies were healthy 9 babies went to nursery and 3 were IUD $(5.56 \%)$.

In a study on CHD and healthy cohorts (9), according to this study abnormal echo findings were observed in $24.6 \%$ cases having ejection fraction below $45 \%$ in $8.1 \%$ Women and RV dysfunction existed in $14.5 \%$ respectively of out of 161 women In study they found $50 \%$ offspring events in cases with abnormal colour Doppler (having abnormal RI and PI values). Although scares, the existing literature on subject suggest that maternal cardiovascular status influences the process of placentation and pregnancy outcome.

In current study among cardiac cases (53\%) babies were healthy and $40 \%$ babies went to nursery and 3 were IUD, comparatively to non cardiac case $82 \%$ were healthy and rest went to nursery and no death were seen among controls. There were more no. of low birth weight babies among delivered heart disease patients 21 babies (39\%). Among non-cardiac patients low birth weight babies were only $10 \%$. Out of that 21 babies, 9 babies were I.U.G.R. and 10 were preterm births in cardiac and 2 were IUD, whereas 5 were IUGR i.e $10 \%$ and no baby were delivered preterm in non cardiac, this is comparable to other studies Another study conducted in Wadia Hospital Bombay, 1992 concluded that, all infants born to mothers with NYHA Class III or IV had intrauterine growth retardation, Hameedet al showed that live birth were 64 out of 66 patients and stillbirth were 2. Mean $( \pm$ SD) birth weight was $2,897( \pm 838) \mathrm{g}$. Preterm delivery was $15(23 \%)$ out of $66 .^{13,14}$ In present study authors observed that 8 cases had Atrial Fibrillation and equal no of cases had preeclampsia $9.25 \%$ and gestational hypertensions i.e. $9.25 \%$ (5 cases) and 2 cases each of cardiac complication, CCF and pulmonary edema.

Another study by Pratibha et al showed that Pregnancy induced hypertension was seen in $18 \%$ (36/200), anemia in $7.5 \%(15 / 200) .{ }^{15}$ Eighteen $(9 \%)$ women had associated medical problems. A study done by Presbitero et al reported a lower incidence of maternal death and other serious complications in women with class I and II heart disease. ${ }^{16}$ Study carried out in Germany. ${ }^{2}$ Pregnancy outcomes were analyzed in 93 consecutive women with heart disease, monitored in a single-centre cohort between 1996 and 2006. Severe maternal complications developed in $12.9 \%$ of all women: $6.5 \%$ heart failure, $3.2 \%$ arrhythmias, and $2.2 \%$ thrombotic complications in uteroplacental flow patterns.

In this study there was 1 maternal mortality out of 54 cases. 2 serious patients had LAMA, so we lost their outcome. That mortality was in gravid 2 who had I.U.D. She had pulmonary edema and CCF leading to peripheral circulatory failure an in our study maternal mortality rate was $1.85 \%$. Early hospitalization, evaluation by a multidisciplinary approach, including cardiologists, together with closer monitoring probably contributed significantly to the fact that there were only 1 maternal death in this study. 


\section{CONCLUSION}

The management of pregnant woman with heart disease requires a multidisciplinary team for optimal maternal and fetal outcome.

Every preventive measure for the women at risk, in our setup we have to searched for simple means of identifying 'at risk' cardiac by practitioners, which would prompt earlier referral for echo-Doppler evaluation and this leaves the practitioner with the sobering reality that clinical assessment remains a prerequisite in identifying symptoms and signs suggestive of cardiac disease, which would determine the need for echocardiographic evaluation, which accurately diagnosed the nature and severity of cardiac lesion,

Uteroplacental flow patterns and cardiovascular parameters differ between women with heart diseases and healthywomen. In women with $\mathrm{CHD}$, ventricular function as well as valvular function are related to uteroplacental flow patterns, while UDF is predictive of obstetric and offspring events. Vaginal delivery is safer and caesarean section should be reserved only for obstetric indications with access to cardiac intensive care units. Majority of pregnancies complicated by heart disease in this study had uneventful course with a favorable outcome for both the mother and the baby.

\section{ACKNOWLEDGMENTS}

Authors would like to thank Dr. Nilesh Dalal, Professor \& Head of Department of Obstetrics and Gynaecology, M.G.M. Medical College and M.Y. Hospital, Indore for allowing us to publish this paper. We are thankful to our parents for their kind cooperation.

Funding: No funding sources

Conflict of interest: None declared

Ethical approval: The study was approved by the Institutional Ethics Committee of MGM Medical College and M.Y. Hospital Indore

\section{REFERENCES}

1. Weiss BM, von Segesser LK, Alon E, Seifert B, Turina Ml. Outcome of cardiovascular surgery and pregnancy: A systematic review of the period 1984-1996. Am J Obstet Gynecol. 1998;179:1643-53.

2. Stangl V, Schad J, Gossing G, Borges A, Baumann G, Stangl K. Maternal heart disease and pregnancy outcome: A single-centre experience. Eur J Heart Fail. 2008;10(9):855-60.

3. Siu SC, Sermer M, Colman JM et al. Prospective multicenter study of pregnancy outcomes in women with heart disease. Circulation. 2001;104(5):515-21.
4. Khairy P, Ouyang DW, Fernandes SM, Lee-Parritz A, Economy KE, Landzberg MJ. Pregnancy outcomes women with congenital heart disease. Circulation. 2006;113(4):517-24.

5. Drenthen W, Pieper PG, Ploeg M, Voors AA, RoosHesselink JW, Mulder BJ, et al. Risk of complications during pregnancy after Senning or Mustard (atrial) repair of complete transposition of the great arteries. Eur Heart J. 2005;26(23):2588-95.

6. Drenthen W, Pieper PG, Roos-Hesselink JW, van Lottum WA, Voors AA, Mulder BJ, et al. Outcome of pregnancy in women with congenital heart disease: a literature review. J Am Coll Cardiol. 2007;49(24):230311.

7. Drenthen W, Boersma E, Balci A et al. Predictors of pregnancy complications in women with congenital heart disease. Eur Heart J. 2010; 31(17):2124-32.

8. Cunningham, Leveno. Cardiovascular disorder in pregnancy, In textbook of Williams, 24th ed. Mc Graw hill education, New York; 2014: 973-999.

9. Balci, A. Pregnancy and outcome in women with congenital heart disease Groningen: s.n.7. Chapter 6; Pregnancy and outcome in women with congenital heart disease Groningen: s.n.7; 2012.

10. Sawhney H, Aggarwal N, Suri V, Vasishta K, Sharma Y, Grover A. PGI CHANDIGARH. PMID: 12527454

11. Hameed A, Karaalp IS, Tummala PP, Wani OR, Canetti M, Akhter MW, et al. The effect of valvular heart disease on maternal and fetal outcome. J Am Coll Cardiol. 2001;37(3):893-9.

12. Campos O1, Andrade JL, Bocanegra J, Ambrose JA, Carvalho AC, Harada K, et al. Physiologic multivalvular regurgitation during pregnancy: a longitudinal Doppler echocardiographic study. Int J Cardiol. 1993;40:265-72.

13. Mane SV, Gharpure VP. Merchant. R H Indian-Pediatr. 1993;30(12):1407-11.

14. Nieminen HP, Jokinen EV, Sairanen HI. Late results of pediatric cardiac surgery in Finland: a population-based study with $96 \%$ follow-up. Circulation. 2001;104(5):570-5.

15. Pratibha D, Srilakshmi Y, Kiranmai D, Swathi G. Pregnancy in cases of congenital heart disease, J Obstet Gynecol India. 2010;60(1):33-7.

16. Presbitero $\mathrm{P}$, Somerville J, Stone S, Aruta E, Spiegelhalter P, Rabajolo F. Pregnancy in cyanotic congenital heart disease. Circulation 1994;89:2673-6.

Cite this article as: Mathuriya G, Gondiya $P$, Jain AK. A prospective comparative study on uteroplacental blood flow, cardiac function and pregnancy outcome in women with heart disease and normal healthy pregnant women. Int J Reprod Contracept Obstet Gynecol 2018;7:2921-5. 